El equipo docente y sus tópicos fueron los siguientes. Profa ${ }^{a}$ Dra. $\mathrm{D}^{\mathrm{a}}$. Amelia Castresana, Catedrática U. de Salamanca: "Deber de corrección, información y bona fides en la negocialidad"; Profa. Dra. Da. Carla Masi Doria, Directora del Departamento Derecho Romano U. Federico II de Nápoles: “Apuntes sobre la relación entre economía, sociedad y derecho privado en la experiencia romana"; Prof. Dr. D. Gianni Santucci, Ordinario U. de Trento: "La 'utilitas contrahentium' en Roma y hoy”; Prof. Dr. Dr. h. c. (mult.) D. Michael Rainer, ordinario U. de Salzburgo: "Las funciones de la 'lex commissoria' y la reserva de dominio en la compraventa"; Profa. Dra. Da. LetiziaVacca, ordinaria U. de Roma III: "Garantía y responsabilidad en la compraventa. Tradición romanista y problemas dogmáticos actuales"; Prof. Dr. D. Luigi Garofalo, ordinario U. de Padova: "La posesión derivada de la actividad negocial. Perfiles romanistas y problemas actuales"; Prof. Dr. D. Boudewijn Sirks, Regius Professor U. de Oxford: “La 'laesio enormis' en la compraventa"; Prof. Dr. Dr. h. c. (mult.) D. Andreas Wacke, ordinario emérito U. de Colonia: "La evolución de las reformas al BGB" y "La imagen del hombre a través del derecho privado".

Para la presente edición, contamos con el respaldo de nuestro Proyecto Anillo-CONICYT, SOC 1111, y el patrocinio de la Excelentísima Corte Suprema de Chile, la Honorable Cámara de Diputados de Chile, la Embajada de Chile en España y su embajador, Señor D. Sergio Romero, la Fundación Chile-España y las Facultades chilenas de Derecho de la Pontificia Universidad Católica de Chile, Pontificia Universidad Católica de Valparaíso, Universidad de los Andes y de la Universidad Gabriela Mistral. Por supuesto, debe reconocerse especialmente la amabilidad y colaboración invariables de la Universidad de Salamanca.

Patricio-Ignacio Carvajal Pontificia Universidad Católica de Chile

\title{
VIII Curso Interuniversitario de Profundización en Derecho Privado Romano, "Cómo profundizar en el Libro II del Código Civil", Santiago y Valparaíso, 6 DE AGOSTO A 5 DE SEPTIEMBRE DE 2013
}

Desde el año 2006, los estudiantes de Derecho de todas las Facultades de Derecho chilenas tienen la oportunidad de asistir a los cursos que imparten los profesores de derecho romano en distintas sedes. Esto permite que los alumnos conozcan compañeros, profesores y dependencias de otras universidades, lo cual constituye una experiencia de suyo interesante. Pero, por sobre todo, permite a los estudiantes desarrollar aún más sus conocimientos con una o dos sesiones semanales que despiertan vivo interés. De hecho, este año se matricularon 245 alumnos, con lo cual este curso sigue siendo la actividad jurídica extraprogramática con mayor poder de convocatoria entre los estudiantes.

La opción metodológica en estos cursos orientados a los jóvenes, consiste en 
destacar el papel del derecho romano como herramienta de interpretación del derecho actual. Para esta octava edición, dicha opción metodológica ha quedado más aún en evidencia, no sólo por el título, sino por nuestra invitación a los colegas del derecho civil para que nos colaboren haciendo la introducción a las instituciones estudiadas. Los colegas del derecho romano, en tanto, se concentran en trazar las líneas de continuidad y cambio entre la experiencia romana y actual.

Como Director de este Curso Interuniversitario, quiero agradecer a todas las instituciones organizadoras de cada sesión y a los profesores interviniente. En la sesión organizada por la Universidad Diego Portales sobre "La definición de la posesión en el Código Civil”, intervinieron los profesores Raúl Lecaros Zegers y Francisco Samper Polo. En aquella que organizó la Universidad Gabriela Mistral acerca de "La definición del dominio en el Código Civil", impartieron lecciones los profesores Hernán Corral y Cristian Aedo. En la que tocó organizar a la Universidad de los Andes en torno al tema: "Las garantías reales y el desposeimiento", se contó con la palabra de los profesores Marcelo Barrientos y Patricio Lazo. La sesión organizada por la Universidad de Chile: "El título y el modo en el Código Civil”, estuvo a cargo de los profesores Íñigo de la Maza y María de los Ángeles Soza. La correspondiente a la Universidad Andrés Bello sobre: "Los errores en la tradición” contó con las pareticipación de los profesores Rodrigo Momberg y Lilian San Martín. La que tomo bajo su alero la Universidad Alberto Hurtado: "Facultades del dominio y derechos reales sobre cosa ajena", recibió a los profesores Marcelo Nasser y Carmen Domínguez. La sesión asignada a la Pontificia Universidad Católica de Chile sobre: "Abuso del derecho de propiedad", fue desarrollada por los profesores Cristián Banfi y Juan David Terrazas. En fin, en la sesión correspondiente a la Universidad de Valparaíso: "Las cosas comunes a todos los hombres" tomaron parte los profesores Rodrigo Míguez, Claudia Cozzani y Alejandro Guzmán.

Esta actividad, también concerniente al Proyecto Anillo-CONICYT, SOC 1111, es sin duda una de las mayores contribuciones a la formación de las futuras generaciones de juristas.

Patricio-Ignacio Carvajal Pontificia Universidad Católica de Chile

\section{Proyecto Anillo-CONiCyT "Estudios históRICO-DOG- MÁTICOS DE DERECHO PATRIMONIAL PRIVADO: UNA MIRA- DA A LOS ARTÍ́CUlOS DE LOS LIBROS II Y IV DEL CÓDIGO Civil de CHILE”, CÓdigo SOC 1111}

Los proyectos "Anillo" de investigación asociativa de la Comisión Nacional de Investigación Científica y Tecnológica (CONICYT) corresponden a los de mayor envergadura dentro del concierto académico chileno. Por ello, es digno de destacarse en estas páginas que el primer y, hasta el momento, único proyecto 